\title{
ИНТЕГРАЦИОННАЯ ПОЛИТИКА ОБЩЕСТВА И ОТНОШЕНИЕ К МИГРАНТАМ ПРИНИМАЮЩЕГО НАСЕЛЕНИЯ: ИССЛЕДОВАНИЕ В 17 ЕВРОПЕЙСКИХ СТРАНАХ
}

\section{A.H. TATAPKO}

${ }^{a}$ Национальный исследовательский университет «Высшая школа экономики», 101000, Россия, Москва, ул. Мясниикая, д. 20

\section{Резюме}

Современный мир характеризуется активными миграционными процессами, и различные страны реагируют на эту реальность по-разному. Одни страны более открыты к мигрантам, другие - менее. В социальных науках изучались различные эффекты интеграционной миграционной политики, прежде всего для мигрантов. Связь интеграционной миграционной политики с установками этнического большинства изучена меньше. Есть данные, показывающие, что мультикультурная политика общества и политика, направленная на интеграцию мигрантов, связана с позитивными установками по отношению к мигрантам и снижением воспринимаемой угрозы. С другой стороны, есть данные, указывающие на то, что открытая иммиграционная политика общества может встречать сопротивление со стороны представителей принимающего населения. Опираясь на данные европейских стран, мы рассмотрели связь восьми показателей иммиграционной политики, составляющих индекс интеграционной политики в отношении мигрантов (MIPEX), с тремя переменными, характеризующими отношение к мигрантам и миграции в целом (допустимость миграции, польза миграции, институциональная поддержка миграции). В исследовании нами использовались данные индекса интеграционной миграционной политики (MIPEX) за 2014 г., а также показатели отношения к мигрантам в 17 европейских странах по данным Европейского социального исследования (ESS) (всего более 30000 респондентов) за 2016 г. Такой дизайн позволил нам разнести во времени причину (иммиграционную политику) и возможное следствие (отношение к мигрантам). Из данных ESS мы выбирали только результаты ответов представителей этнического большинства. Для обработки использовалось многоуровневое моделирование структурными уравнениями в программе MPLUS. Результаты исследования показали неоднозначность связи как всего индекса MIPEX, так и его составляющих с различными представлениями принимающего населения о мигрантах и миграции. В работе обсуждается, какие из аспектов интеграционной политики (на примере европейских данных) в отношении мигрантов имеют позитивные, а какие - негативные связи с отношением принимающего населения к мигрантам.

Ключевые слова: мультикультурализм, МIPEX, мигранты, отношение к мигрантам. 


\section{Введение}

Большинство европейских стран в той или иной мере сталкиваются с интенсивной иммиграцией. В последние годы в связи с рядом военных и политических событий (например, политический кризис на Украине, война в Сирии) интенсивность миграции в европейские страны выросла, что привело к миграционному кризису в Европе (Bodziany, 2017). При этом различные страны в разной мере открыты для миграции и интеграции мигрантов в общество. В этой связи представляется важным изучение различных эффектов интеграционной миграционной политики. Интеграционная политика в отношении иммигрантов чаще всего определяется как институциональная практика, принятая государственными учреждениями для решения проблемы расселения и адаптации иммигрантов в принимающих обществах (Bourhis et al., 1997).

Интеграционная миграционная политика является отражением мультикультурной политики общества. Такие составляющие политики мультикультурализма, как мультикультурное образование, специальные программы по предоставлению различных льгот мигрантам и т.п., имеют для них позитивные с психологической точки зрения эффекты, в частности способствуют снижению воспринимаемой дискриминации и улучшают адаптацию (Koopmans et al., 2012; Wright, Bloemraad, 2012). Также результаты исследований показывают, что политика мультикультурализма, культивируемая в обществе, позитивно влияет на межэтнические отношения в обществе в целом (Ely, Thomas, 2001; Plaut et al., 2009; Richeson, Nussbaum, 2004; Ryan et al., 2007; Todd, Galinsky, 2012; Wolsko et al., 2000, 2006). Это немаловажно, поскольку общество, разрываемое внутренними межгрупповыми конфликтами, не может гармонично развиваться и эффективно конкурировать с другими странами в современных реалиях.

Однако нельзя сказать, что в повседневной жизни общества позитивные эффекты мультикультурализма хорошо ощутимы для представителей принимающего населения. В результате мультикультурные практики порой встречают сопротивление со стороны представителей этнического большинства в некоторых сферах общественной жизни, например на рабочих местах (Thomas, Plaut, 2008). Пожалуй, основной причиной сопротивления мультикультурализму со стороны большинства является рост воспринимаемой угрозы (Verkuyten, 2009), который сопряжен с увеличением численности инокультурных мигрантов. Этническое большинство воспринимает рост численности представителей меньшинств и мигрантов как угрозу безопасности, статусу, ценностям своей группы, а также ее экономическим и политическим интересам (Kaiser, Pratt-Hyatt, 2009; Yogeeswaran et al., 2012; Ginges, Cairns, 2000; Stephan, Renfro, 2002).

Таким образом, в целом данные исследований показывают, что политика мультикультурализма позитивно влияет на жизнь мигрантов и этнических меньшинств. Что же касается этнического большинства, то данные относительно того, как связана мультикультурная политика с отношением этнического 
большинства к мигрантам, противоречивы. С одной стороны, мультикультурная политика или интеграционная политика общества в отношении мигрантов может способствовать позитивному отношению к мигрантам и налаживанию позитивных межэтнических отношений в обществе, но, с другой стороны, может встречать сопротивление со стороны этнического большинства или принимающего населения из-за растущей воспринимаемой угрозы в связи с притоком мигрантов.

Интеграционная политика в отношении мигрантов может быть расположена на условном континууме от «ограничительной» до «разрешительной» (Bourhis et al., 1997; Geddes, 2003). Специальный Индекс интеграционной политики в отношении мигрантов (MIPEX) был разработан Британским Советом и Группой миграционной политики. Он был создан для измерения и сопоставления иммиграционных политик в разных странах. MIPEX включает оценку интеграционной политики государства в отношении мигрантов в следующих восьми сферах: 1) мобильность рынка труда, 2) воссоединение семей иностранных граждан, 3) образование, 4) политическая вовлеченность, 5) институт вида на жительство, 6) доступ к гражданству, 7) антидискриминационные меры и 8) здравоохранение.

Исследования, проведенные с использованием индекса MIPEX, показали, что интеграционная миграционная политика имеет ряд позитивных эффектов для мигрантов и иммигрантов (Favell, 2001; Jacobs, Herman, 2009). Также литературные данные указывают на то, что более открытая иммиграционная политика способствует снижению воспринимаемой угрозы со стороны мигрантов у представителей принимающего населения (Schlueter et al., 2013). Следовательно, если отношение этнического большинства к мигрантам улучшается, это способствует лучшей адаптации мигрантов. Интеграционная миграционная политика в области образования способствует более успешной общей социальной инклюзии детей иммигрантов и более успешному построению ими отношений с одноклассниками и учителями (Ibid.).

В целом систематический обзор существующих исследований (Bilgili et al., 2015), выполненных при помощи MIPEX, показывает, что как инклюзивная миграционная политика в целом, так и ее отдельные составляющие действительно способствуют лучшей адаптации мигрантов.

Однако исследований того, какие эффекты открытая иммиграционная политика несет для представителей этнического большинства, недостаточно. Есть данные, указывающие на то, что в целом инклюзивная иммиграционная политика может снижать воспринимаемую угрозу у представителей принимающего населения (Schlueter et al., 2013). Но связь отдельных восьми составляющих иммиграционной политики с различными аспектами отношения к мигрантам и миграции не изучалась. Проведенное нами исследование восполняет данный пробел.

Итак, цель настоящего исследования - оценить связь как интеграционной политики общества в целом, так и отдельных ее составляющих с отношением к мигрантам у представителей этнического большинства. Мы пытаемся понять: если общество открыто к мигрантам и предпринимает усилия по их 
интеграции, как в конечном счете это сказывается на отношении к мигрантам принимающего населения? Становится ли отношение более позитивным, открытым, или наступает защитная реакция и отношение становится более закрытым? Или миграционная политика обществ никак не сказывается на отношении принимающего населения к мигрантам? Ответам на эти вопросы посвящено проведенное исследование.

\section{Методика}

\section{Выборка}

Для проверки наших предположений мы использовали данные последней, восьмой волны Европейского социального исследования (ESS) за 2016-2017 гг., а также данные MIPEX за 2014 г. Для анализа мы отобрали 17 стран, данные которых одновременно присутствовали в обеих базах. Далее мы удалили из базы представителей этнических меньшинств, оставив только представителей большинства, поскольку наши предположения касаются именно представителей этнического большинства. Кодировка респондентов в ESS позволяет разделить выборку на тех, кто идентифицирует себя в качестве этнических меньшинств или мигрантов и в качестве этнического большинства. Финальная версия выборки включала 30101 респондента из 17 стран (эти страны представлены в таблице 1). Поскольку данные в ESS всегда репрезентативны, мы для экономии места не приводим детальные характеристики по каждой выборке в каждой стране.

Заметим, что данные за 2014 г. по MIPEX - это самые последние доступные данные этого индекса на момент написания статьи, включающие Россию. Мы использовали ESS не 7-й волны (2014), а 8-й волны (2016) для того, чтобы разнести во времени предполагаемый предиктор - иммиграционную политику, которая исходит сверху, и предполагаемые зависимые переменные - социальное и институциональное доверие людей в обществе, которые могут меняться вследствие различных изменений, происходящих в обществе под влиянием политики, поскольку для изменений в установках и представлениях людей требуется время. Разумеется, мы не можем говорить о причинно-следственной связи, в данном случае мы говорим только о сопряженности.

\section{Переменные}

\section{Независимые переменные}

Мы оценивали интеграционную политику обществ в отношении мигрантов на страновом уровне, соответственно, наши независимые переменные были представлены данными МІРЕХ за 2014 г. В исследовании мы использовали в качестве предиктора как весь индекс полностью, так и восемь его составляющих в отдельности. Использование отдельных составляющих индекса в качестве предикторов установок по отношению к мигрантам позволяет 
точнее увидеть и понять, какие из компонентов иммиграционной политики наиболее заметно связаны с установками принимающего населения, а также какова направленность данной связи. Как общий индекс, так и его составляющие варьируют в соответствии со 100-балльной шкалой, где 0 - отсутствие рассматриваемой практики, 100 - максимальное значение применения данной практики. Соответственно, чем ближе общий индекс к 100 баллам, тем более благоприятной является интеграционная политика в отношении мигрантов в конкретной стране.

\section{Зависимые переменные}

Зависимые переменные в нашем исследовании были представлены латентными факторами, а не композитными оценками. Это было сделано для того, чтобы избежать нивелирования дисперсии зависимых переменных, к чему привело бы вычисление композитных оценок (или средних по шкалам) на таких больших массивах данных.

$\mathrm{C}$ психологической точки зрения зависимые переменные характеризуют представления респондентов о последствиях миграции и отношение к ней. В нашем исследовании близкие по смыслу группы представлений, оцениваемые в ESS, были объединены в соответствующие латентные факторы, получившие общее название.

1. Допустимость миграции для страны в целом, с точки зрения респондента, оценивалась при помощи следующих трех вопросов: (1) «Следует ли позволить людям той же расы или национальности, что и большинство населения (название странь), переезжать жить в нашу страну?», (2) «А как насчет людей, которые по национальности или расовой принадлежности отличаются от большинства населения (название странь)?», (3) «А если говорить о людях из более бедных стран за пределами Европы?». Для ответов на данные вопросы респондентам предлагалась 4-балльная шкала: 1 - Следует позволить многим таким людям переезжать жить в (название странь); 2 - Следует позволить некоторым таким людям переезжать жить в (название странь); 3 Следует позволить переезжать лишь немногим из них; 4 - Никому не разрешать. Ответы респондентов перекодировались, чтобы нарастание согласия с утверждением шло в сторону позитивного полюса шкалы. Мы оценивали данные представления в логике согласия, а не в логике несогласия.

2. Польза миграции для страны, с точки зрения респондента, оценивалась при помощи следующих трех вопросов: (1) «Как вы считаете, то, что люди из других стран переезжают в (название страны), в целом плохо или хорошо сказывается на экономике (название страны)?», (2) «Как вы считаете, приток людей из других стран скорее разрушает или скорее обогащает культуру (название странь)?», (3) «С притоком людей из других стран (название стра$\boldsymbol{H o l )}$ как место для жизни становится лучше или хуже?». В данном случае для ответа предлагалась 10-балльная шкала, где 0 - максимальна степень несогласия с утверждением, а 10 - максимальная степень согласия. 
3. Институииональная поддержка миграции, которая должна быть в стране: (1) «Правительство должно без особых придирок предоставлять людям статус беженцев», (2) «Людям, которые получили статус беженца, должно быть разрешено перевезти также близких членов своей семьи», (3) «Должны ли иммигранты требовать тех же прав и социальных гарантий, что и местное население?». Для ответов на данные вопросы респондентам предлагалась 5балльная шкала от $1-$ Полностью согласен до 5 - Совершенно не согласен. Ответы респондентов перекодировались, чтобы нарастание согласия с утверждением шло в сторону позитивного полюса шкалы. Мы оценивали данные представления в логике согласия.

\section{Контрольные переменные}

Переменнье индивидуального уровня

1. Пол: 1 - мужчины; 2 - женщины.

2. Возраст: респонденты при ответе называли год рождения, соответственно подсчитывался полный возраст на момент проведения опроса.

3. Доход: в ESS в каждой стране респондентов спрашивают об их доходе, но, поскольку уровень жизни и валюты отличаются, в каждой стране, доходу респондента присваивают определенный дециль (т.е. приводят к единой 10балльной шкале). Соответственно, доходы людей разных стран можно сравнивать и использовать для контроля и других вычислений.

Переменные макроуровня

1. Уровень безработицы по странам Европы за 2016 г. Использовались данные сайта «Trading Economics» (https://tradingeconomics.com/countrylist/unemployment-rate).

2) ВВП европейских стран за 2016 г. Использовались данные Международного валютного фонда (http://www.imf.org/).

\section{Обработка данных}

Для обработки эмпирических данных использовалась процедура многоуровневого моделирования структурными уравнениями (Hoyle, 2012; Croon, van Veldhoven, 2007). Данная процедура позволяет провести не только конфирматорный факторный анализ (Jöreskog, 1993) и моделирование при помощи структурных уравнений, но и оценить влияние макропоказателей на микропоказатели, т.е. влияние одних переменных на другие при условии того, что эти переменные находятся на разных уровнях анализа. В нашем случае макропеременная (независимая) была представлена индексом MIPEX или его составляющими, а также в качестве макропеременных включались контрольные переменные. Микропеременные (зависимые) были представлены тремя показателями отношения респондентов к внешней миграции (допустимость миграции, польза миграции, институциональная поддержка миграции). Для осуществления процедуры моделирования использовалась программа MPLUS (Geiser, 2012). 


\section{Результаты}

В таблице 1 представлены значения индекса интеграционной политики в отношении мигрантов, а также его компоненты по семнадцати странам, данные которых использовались в нашем исследовании. Как уже отмечалось, это данные за 2014 г. и все индексы (и сам MIPEX, и его составляющие) варьируют в соответствии со 100-балльной шкалой.

Данные интеграционной политики, приведенные в таблице 1, использовались нами при проведении многоуровневого моделирования структурными уравнениями с целью анализа связи интеграционной политики общества с отношением к мигрантам принимающего населения спустя два года. Для этого мы построили девять моделей - для общего Индекса интеграционной

Таблища 1

\section{Индекс интеграции мигрантов и его компоненты по рассматриваемым} в исследовании странам

\begin{tabular}{|l|c|c|c|c|c|c|c|c|c|}
\hline \multicolumn{1}{|c|}{ Страна } & MIPEX & LMM & FamilyR & Educ & PolotP & PermR & AccTNat & ANTI_D & HEAL \\
\hline Швеция & 78 & 98 & 78 & 77 & 71 & 79 & 73 & 85 & 62 \\
\hline Финляндия & 69 & 80 & 68 & 60 & 79 & 70 & 63 & 77 & 53 \\
\hline Норвегия & 69 & 90 & 63 & 65 & 82 & 70 & 52 & 59 & 67 \\
\hline Бельгия & 67 & 64 & 72 & 61 & 57 & 86 & 69 & 78 & 53 \\
\hline Германия & 61 & 86 & 57 & 47 & 63 & 60 & 72 & 58 & 43 \\
\hline Нидерланды & 60 & 73 & 56 & 50 & 52 & 55 & 66 & 73 & 55 \\
\hline $\begin{array}{l}\text { Великобрита- } \\
\text { ния }\end{array}$ & 57 & 56 & 33 & 57 & 51 & 51 & 60 & 85 & 64 \\
\hline Франция & 54 & 54 & 51 & 36 & 53 & 48 & 61 & 77 & 50 \\
\hline Ирландия & 52 & 38 & 40 & 30 & 73 & 49 & 59 & 66 & 58 \\
\hline Австрия & 50 & 64 & 50 & 47 & 38 & 57 & 26 & 57 & 63 \\
\hline Швейцария & 49 & 59 & 48 & 42 & 58 & 51 & 31 & 31 & 70 \\
\hline Эстония & 46 & 73 & 67 & 58 & 21 & 71 & 18 & 32 & 27 \\
\hline $\begin{array}{l}\text { Чешская } \\
\text { Республика }\end{array}$ & 45 & 52 & 57 & 38 & 21 & 51 & 49 & 48 & 44 \\
\hline Исландия & 45 & 51 & 59 & 23 & 67 & 62 & 53 & 5 & 40 \\
\hline Словения & 44 & 38 & 80 & 26 & 23 & 61 & 41 & 67 & 18 \\
\hline Польша & 41 & 38 & 65 & 20 & 6 & 66 & 56 & 52 & 26 \\
\hline Россия & 28 & 40 & 42 & 18 & 9 & 33 & 40 & 20 & 18 \\
\hline
\end{tabular}

Примечание. MIPEX - Интеграционная политика в отношении мигрантов; LMM - мобильность рынка труда; FamilyR - воссоединение семей иностранных граждан; Educ - образование; PolotP - политическая вовлеченность; PermR - институт вида на жительство; AccTNat доступ к гражданству; ANTI_D - антидискриминационные меры; HEAL - здравоохранение. 
политики обществ в отношении мигрантов и для каждого из восьми компонентов, составляющих этот индекс, что позволило оценить связь каждого из компонентов индекса с разными аспектами отношения к мигрантам. В каждой модели было по три зависимых переменных (латентные факторы, характеризующие отношение к мигрантам), три контрольные переменные микроуровня (пол, возраст, уровень дохода) и две контрольные переменные для макроуровня - ВВП и уровень безработицы в стране.

В таблице 2 приводятся структура нагрузки латентных переменных, а также связи между ними для макроуровня и микроуровня. Характеристики моделей, в которых были задействованы эти латентные переменные, приводятся в таблице 4. Опираясь на таблицу 2, можно сказать, что все переменные входят в соответствующие факторы со статистически значимой нагрузкой на обоих уровнях анализа.

В таблице 3 представлены связи зависимых переменных с контрольными переменными на микро- и макроуровне анализа.

Из таблицы 3 следует, что статистически значимое, но слабое влияние на зависимые переменные оказывают контрольные переменные микроуровня. Женщины более терпимы к мигрантам, чем мужчины, и оценивают допустимость миграции, пользу миграции и необходимость институциональной поддержки миграции выше, чем мужчины. Люди старшего возраста более негативно оценивают допустимость миграции, но признают ее пользу. Уровень дохода европейцев связан с допустимостью миграции, оценкой ее пользы и институциональной поддержи позитивно, т.е. более состоятельные люди более лояльны к мигрантам. На макроуровне контрольные переменные не показали статистически значимой связи с зависимыми переменными исследования, однако хотелось бы обратить внимание на их связь с одной из переменных - «допустимость миграции». Связи в данном случае не достигают уровня статистической значимости, но мы можем видеть общую тенденцию: а) уровень ВВП в стране позитивно связан с представлениями ее граждан о допустимости, приемлемости внешней миграции $(0.147)$; б) уровень безработицы в стране отрицательно связан с представлениями граждан о допустимости миграции (-0.222). Обе связи достаточно логичны.

В таблице 4 приводятся результаты многоуровневого моделирования связи интеграционной политики и отношения к мигрантам принимающего населения. Данные таблицы 4 приведены с учетом контрольных переменных, указанных в таблице 3 . Нам не удалось построить одну из моделей вследствие того, что показатели пригодности были слабыми. Это модель связей последнего компонента MIPEX «Доступ мигрантов к здравоохранению» с тремя переменными, характеризующими отношение к мигрантам. По остальным семи составляющим MIPEX и самому MIPEX модели имеют удовлетворительные индексы пригодности.

Данные, приведенные в таблице 4, указывают на то, что как весь MIPEX, так и отдельные его составляющие связаны с некоторыми из представлений, характеризующих отношение доминирующего населения к мигрантам. Поэтому наше общее предположение о том, что открытая миграционная политика 
Структура, нагрузки и интеркорреляции зависимых переменных (все коэффициенты стандартизированы)

\begin{tabular}{|c|c|c|}
\hline Факторы и переменные & Микроуровень & Макроуровень \\
\hline \multicolumn{3}{|l|}{ (F1) Допустимость миграции } \\
\hline $\begin{array}{l}\text { «Следует ли позволить людям той же расы или } \\
\text { национальности, что и большинство населения } \\
(\text { название странь), переезжать жить в нашу страну?» }\end{array}$ & $0.773^{* * *}$ & $0.902^{* * *}$ \\
\hline $\begin{array}{l}\text { «А как насчет людей, которые по национальности } \\
\text { или расовой принадлежности отличаются от } \\
\text { большинства населения (название страны)?» }\end{array}$ & $0.898^{* * *}$ & $0.975^{* * *}$ \\
\hline $\begin{array}{l}\text { «А если говорить о людях из более бедных стран за } \\
\text { пределами Европы?» }\end{array}$ & $0.768^{* * *}$ & $0.995^{* * *}$ \\
\hline \multicolumn{3}{|l|}{ (F2) Польза миграции } \\
\hline $\begin{array}{l}\text { «Как вы считаете, то, что люди из других стран } \\
\text { переезжают в (название страны), в целом плохо или } \\
\text { хорошо сказывается на экономике (название страны)?» }\end{array}$ & $0.545^{* * *}$ & $0.841^{* * *}$ \\
\hline $\begin{array}{l}\text { «ак вы считаете, приток людей из других стран } \\
\text { скорее разрушает или скорее обогащает культуру } \\
(\text { название страны)?» }\end{array}$ & $0.589 * * *$ & $0.929^{* * *}$ \\
\hline $\begin{array}{l}\text { «С притоком людей из других стран (название страны) } \\
\text { как место для жизни становится лучше или хуже?» }\end{array}$ & $0.542^{* * *}$ & $10.00 * * *$ \\
\hline \multicolumn{3}{|l|}{ (F3) Институциональная поддержка миграции } \\
\hline $\begin{array}{l}\text { «Правительство должно без особых придирок } \\
\text { предоставлять людям статус беженцев» }\end{array}$ & $0.626^{* * *}$ & $0.811^{* * *}$ \\
\hline $\begin{array}{l}\text { «Людям, которые получили статус беженца, должно } \\
\text { быть разрешено перевезти также близких членов } \\
\text { своей семьи» }\end{array}$ & $0.627^{* * *}$ & $0.851^{* * *}$ \\
\hline $\begin{array}{l}\text { «Должны ли иммигранты требовать тех же прав и } \\
\text { социальных гарантий, что и местное население?» }\end{array}$ & $0.406^{* * *}$ & $0.900 * * *$ \\
\hline \multicolumn{3}{|l|}{ Интеркорреляции между факторами: } \\
\hline F1 и F2 & $0.342^{* * *}$ & 0.071 \\
\hline F1 и F3 & $0.554^{* * *}$ & $0.991^{* * *}$ \\
\hline $\mathrm{F} 2$ и $\mathrm{F} 3$ & $0.452 * * *$ & 0.307 \\
\hline
\end{tabular}
*** $p<0.001$.

общества в конечном итоге будет связана с отношением принимающего населения к мигрантам, оказалось верным. Особенности обнаруженных связей будут рассмотрены в следующем разделе данной статьи. 
Таблица 3

Регрессионные коэффициенты (стандартизированные) связи контрольных переменных с показателями отношения к мигрантам (17 обществ)

\begin{tabular}{|l|c|c|c|}
\hline \multicolumn{1}{|c|}{ Переменные } & $\begin{array}{c}\text { Допустимость } \\
\text { миграции }\end{array}$ & Польза миграции & $\begin{array}{c}\text { Институциональная } \\
\text { поддержка миграции }\end{array}$ \\
\hline Микроуровень: & $0.034^{* * *}$ & $0.048^{* * *}$ & $0.088^{* * *}$ \\
\hline Пол & $-0.033^{* * *}$ & $0.032^{* * *}$ & -0.007 \\
\hline Возраст & $0.013^{*}$ & $0.057^{* * *}$ & $0.030^{* * *}$ \\
\hline Уровень дохода & \multicolumn{5}{|l}{} \\
\hline Макроуровень: & 0.147 & 0.034 & 0.059 \\
\hline ВВП & -0.222 & 0.014 & -0.003 \\
\hline Уровень безработицы &
\end{tabular}

${ }^{* *} p<0.01,{ }^{* * *} p<0.001$.

\section{Обсуждение результатов}

Результаты исследования, проведенного с опорой на данные 17 европейских стран, показывают, что одни аспекты интеграционной политики в отношении мигрантов сопряжены с позитивными представлениями о миграции, но другие - с настороженным отношением к мигрантам. В целом чем более выражена интеграционная политика общества, тем более позитивно люди оценивают допустимость миграции, однако эта связь оказалась статистически не значимой. Эти данные согласуются с существующими исследованиями, которые показали, что инклюзивная иммиграционная политика связана с позитивным отношением к иммигрантам со стороны представителей принимающего населения (Jacobs, Herman, 2009), а также такая политика снижает уровень воспринимаемой угрозы со стороны принимающего населения в отношении мигрантов (Schlueter et al., 2013)

Более значимой оказалась отрицательная связь МIPEX с оценкой людьми пользы миграции, т.е. чем больше в общество прибывает мигрантов, тем сильнее коренное население этого общества начинает сомневаться, что приток мигрантов обогащает культуру их общества, позитивно сказывается на экономике, а их страна как место для жизни становится лучше. Эти результаты могут быть объяснены с привлечением теории интегральной угрозы (Stephan, Renfro, 2002) и теории межгрупповой тревожности (Stephan, 2014). Благоприятная иммиграционная политика приводит к увеличению числа мигрантов в обществе, что может вызывать у принимающего населения тревогу и чувство угрозы. В результате люди не будут позитивно оценивать пользу от миграции. При этом нет значимых отрицательных связей с двумя другими группами представлений о миграции и мигрантах: «допустимость миграции» и «институциональная поддержка миграции». Нельзя сказать, что благоприятная 
Таблица 4

Результаты многоуровневого регрессионного анализа связи интеграционной политики в отношении мигрантов и отношения к мигрантам принимающего населения

(17 стран, 30101 респондент)

\begin{tabular}{|c|c|c|c|c|}
\hline Предикторы & $\begin{array}{c}\text { Зависимые } \\
\text { переменные }\end{array}$ & $\beta$ & $\mathbf{R}^{2}$ & $\begin{array}{c}\text { Индексы пригодности } \\
\text { модели }\end{array}$ \\
\hline \multirow{3}{*}{$\begin{array}{l}\text { 1. МIPЕХ - Интеграц. } \\
\text { политика в отношении } \\
\text { мигрантов (общий индекс) }\end{array}$} & ДМ & 0.20 & 0.06 & \multirow{3}{*}{$\begin{aligned} \chi^{2} & =1302.5 ; \mathrm{df}=106 ; \\
C F I & =0.983 ; \mathrm{TLI}=0.976 ; \\
& \text { RMSEA }=0.019\end{aligned}$} \\
\hline & ПМ & $-0.49^{*}$ & 0.22 & \\
\hline & ИПМ & -0.11 & 0.02 & \\
\hline \multirow{3}{*}{$\begin{array}{l}\text { 2. Мобильность рынка } \\
\text { труда }\end{array}$} & ДМ & 0.02 & 0.02 & \multirow{3}{*}{$\begin{aligned} \chi^{2} & =1296.7 ; \mathrm{df}=106 ; \\
C F I & =0.983 ; \text { TLI }=0.976 ; \\
& \text { RMSEA }=0.019\end{aligned}$} \\
\hline & $\Pi \mathrm{M}$ & $-0.50 * *$ & 0.25 & \\
\hline & ИПМ & -0.34 & 0.12 & \\
\hline \multirow{3}{*}{$\begin{array}{l}\text { 3. Воссоединение семей } \\
\text { иностранных граждан }\end{array}$} & ДМ & 0.35 & 0.09 & \multirow{3}{*}{$\begin{array}{c}\chi^{2}=1290.7 ; \mathrm{df}=106 ; \\
C F I=0.983 ; \text { TLI }=0.976 ; \\
\quad \text { RMSEA }=0.019\end{array}$} \\
\hline & $\Pi \mathrm{M}$ & 0.09 & 0.007 & \\
\hline & ИПМ & 0.04 & 0.003 & \\
\hline \multirow{3}{*}{$\begin{array}{l}\text { 4. Доступ мигрантов к } \\
\text { образованию }\end{array}$} & ДМ & -0.10 & 0.03 & \multirow{3}{*}{$\begin{array}{c}\chi^{2}=1290.9 ; \mathrm{df}=106 ; \\
C F I=0.983 ; \text { TLI }=0.976 \\
\text { RMSEA }=0.019\end{array}$} \\
\hline & ПМ & $-0.63^{* * *}$ & 0.37 & \\
\hline & ИПМ & $-0.47^{*}$ & 0.21 & \\
\hline \multirow{3}{*}{$\begin{array}{l}\text { 5. Политическая } \\
\text { вовлеченность мигрантов }\end{array}$} & ДМ & $0.46^{*}$ & 0.22 & \multirow{3}{*}{$\begin{aligned} \chi^{2} & =1306.09 ; \mathrm{df}=106 ; \\
C F I & =0.983 ; \text { TLI }=0.976 \\
& \text { RMSEA }=0.019\end{aligned}$} \\
\hline & ПМ & $-0.49^{*}$ & 0.23 & \\
\hline & ИПМ & 0.36 & 0.13 & \\
\hline \multirow{3}{*}{$\begin{array}{l}\text { 6. Институт вида на } \\
\text { жительство }\end{array}$} & ДМ & 0.25 & 0.06 & \multirow{3}{*}{$\begin{aligned} \chi^{2} & =1291.04 ; \mathrm{df}=106 ; \\
C F I & =0.983 ; \text { TLI }=0.976 \\
& \text { RMSEA }=0.019\end{aligned}$} \\
\hline & ПМ & -0.12 & 0.01 & \\
\hline & ИПМ & -0.09 & 0.01 & \\
\hline \multirow{3}{*}{ 7. Доступ к гражданству } & ДМ & $0.41^{*}$ & 0.18 & \multirow{3}{*}{$\begin{aligned} \chi^{2} & =1318.2 ; \mathrm{df}=106 ; \\
C F I & =0.983 ; \text { TLI }=0.976 ; \\
& \text { RMSEA }=0.019\end{aligned}$} \\
\hline & ПМ & 0.05 & 0.03 & \\
\hline & ИПМ & 0.09 & 0.02 & \\
\hline \multirow{3}{*}{$\begin{array}{l}\text { 8. Антидискриминацион- } \\
\text { ные меры }\end{array}$} & ДМ & 0.10 & 0.03 & \multirow{3}{*}{$\begin{aligned} \chi^{2} & =1319.7 ; \mathrm{df}=106 ; \\
C F I & =0.983 ; \text { TLI }=0.976 ; \\
& \text { RMSEA }=0.019\end{aligned}$} \\
\hline & $\Pi \mathrm{M}$ & -0.31 & 0.07 & \\
\hline & ИПМ & -0.19 & 0.03 & \\
\hline
\end{tabular}

${ }^{*} p<0.05,{ }^{* *} p<0.01, * * * p<0.001$.

Примечание. Обозначения зависимых переменных: ДМ - Допустимость миграции, ПМ Польза миграции, ИПМ - Институциональная поддержка миграции.

и открытая иммиграционная политика делает людей более нетерпимыми к мигрантам. В целом представления о допустимости миграции и важности институциональной поддержки мигрантов не меняются. 
Если просмотреть связи компонентов MIPEX с тремя рассматриваемыми в исследовании блоками представлений о мигрантах, то можно увидеть, что многие из его компонентов связаны именно с представлениями о пользе миграции. Точнее, мы можем видеть отрицательные связи представлений о пользе миграции с такими компонентами MIPEX, как: «мобильность рынка труда», «доступ мигрантов к образованию», «политическая вовлеченность мигрантов». Когда коренное население видит, что мигранты имеют широкие возможности на рынке труда, доступ к образованию в стране и возможность оказывать влияние на политические процессы в стране, то межгрупповая тревожность, связанная с включенностью мигрантов в жизнь общества, возрастает и принимающее население начинает сомневаться в пользе миграции для страны. Вероятно, по той же причине доступность образования для мигрантов статистически значимо отрицательно связана с представлениями о том, что должна быть институциональная поддержка мигрантов. Аналогичная отрицательная связь есть у компонента «мобильность рынка труда», но она не дотягивает до уровня значимости.

Наряду с отрицательными связями, некоторые из компонентов MIPEX демонстрируют и позитивные связи с отношением к мигрантам. В частности, доступ к гражданству позитивно связан с представлениями о допустимости миграции. В данном случае логичнее было бы предположить, что в обществах, где население считает, что миграция допустима, возможности доступа к гражданству будут также выше. Чтобы подтвердить такое предположение, представления людей должны быть измерены не через два года после оценки интеграционной политики общества, а до ее введения. Однако мы можем предположить, что просто в тех обществах, где мигранты имеют легкий доступ к гражданству и допустимость миграции оценивается населением выше, такая корреляция существует сама по себе, даже если мы не разнесем во времени эти две переменные как причину и следствие.

Интересной является позитивная связь политической вовлеченности мигрантов и допустимости миграции, что противоречит отрицательной связи этого аспекта миграционной политики с представлениями о пользе миграции. Прежде всего, нужно обратить внимание на то, что эти две зависимые переменные не связаны на макроуровне (таблица 2), поэтому в этих двух связях нет противоречия. Видимо, если представители коренного населения видят, что мигранты участвуют так же, как и они сами, в политической жизни общества, они в большей мере начинают воспринимать мигрантов как равноправных граждан общества и, соответственно, допустимость миграции становится для них более приемлемой.

Некоторые из составляющих индекса интеграционной политики в отношении мигрантов не связаны статистически значимо с отношением к мигрантам в европейских странах, включая Россию. В частности, это такие компоненты, как «воссоединение семей иностранных граждан», «институт вида на жительство» и «антидискриминационные меры».

Таким образом, если обобщить полученные результаты ряда стран Европы, включая Россию, мы можем сказать, что благоприятная миграционная политика 
связана (при контроле пола, возраста, дохода, ВВП и уровня безработицы) с отношением к мигрантам следующим образом. В целом на уровне тенденции люди в странах с интеграционной политикой в отношении мигрантов рассматривают миграцию как вполне допустимое и приемлемое явление. Но еще раз подчеркнем - эта связь с общим индексом присутствует на уровне тенденции, на которую ее «вытягивают» такие компоненты MIPEX, как «доступ к гражданству» и «политическая вовлеченность мигрантов». Более сильной и значимой является отрицательная связь MIPEX, а также большинства его компонентов с представлениями жителей европейских стран о пользе миграции. С представлениями необходимости институциональной поддержки мигрантов MIPEX и его составляющие практически не связаны.

Чем эти результаты могут оказаться полезными для России? Конечно, контекст и история имеют большое значение для формирования отношения к мигрантам. Но если от них абстрагироваться, то можно сказать, что политика, направленная на интеграцию мигрантов, обязательно должна сопровождаться дополнительными мерами по работе с принимающим населением, которые позволили бы снизить воспринимаемую угрозу (Stephan, Renfro, 2002) и межгрупповую тревожность (Stephan, Stephan, 1985; Stephan, 2014). Это позволит минимизировать вероятность напряженности в отношениях мигрантов и принимающего населения, а также снизить вероятность появления тех же проблем межкультурного взаимодействия, вследствие которых некоторые из европейских лидеров высказывались критически о результатах политики мультикультурализма в Европе (Koopmans, 2013).

\section{Заключение}

На примере 17 европейских стран мы выявили связи индекса интеграционной политики обществ в отношении мигрантов, а также его отдельных составляющих с различными аспектами представлений о мигрантах и миграции в этих обществах.

Основным ограничением нашего исследования служит то, что нам сложно однозначно говорить о том, что отношение к мигрантам является следствием политики обществ, а не наоборот. В целом, конечно, было бы логично предположить, что социальные представления людей, существующие в обществе, в конечном итоге воплощаются в официальную миграционную политику обществ. Однако, как уже не раз говорилось, дизайн нашего исследования был построен таким образом, что представления оценивались на два года позже оценки миграционной политики, т.е. они, скорее всего, не могли быть ее причиной. Следующий аргумент состоит в том, что связь большинства различных аспектов миграционной политики с представлениями о мигрантах в основном носит отрицательный характер. Было бы нелогично сказать, что настороженное отношение к мигрантам лежит в основе открытой иммиграционной политики. Скорее наоборот, открытая миграционная политика способна вызвать настороженное отношение к мигрантам со стороны принимающего населения. 
Полученные результаты имеют важное прикладное значение и могут быть полезны для планирования Россией ее собственной интеграционной политики в отношении мигрантов, поскольку Россия находится на одном из ведущих мест в мире по интенсивности внешней миграции.

Ссылки на зарубежные источники см. в разделе References после англоязычного блока.

Татарко Александр Николаевич - профессор, факультет социальных наук, департамент психологии; главный научный сотрудник, Экспертный институт, Международная научноучебная лаборатория социокультурных исследований, Национальный исследовательский университет «Высшая школа экономики», доктор психологических наук.

Сфера интересов: социальный капитал, социально-психологический капитал личности, межэтнические отношения, ценности, аккультурация.

Контакты: tatarko@yandex.ru

\title{
Integration Policy of Society and Attitudes of the Host Population towards Migrants: A Study in 17 European Countries
}

\author{
A.N. Tatarko \\ ${ }^{a}$ National Research University Higher School of Economics, 20 Myasnitskaya Str., Moscow, 101000, \\ Russian Federation
}

\begin{abstract}
Migration processes in today's world are developing rapidly, and different countries respond to this reality in different ways. Some are more open to migrants and their integration, while others are less welcoming. Various effects of integration migration policy, primarily for migrants, were studied in the social sciences. The connection of integration migration policy with the attitudes of ethnic majority towards migrants has been studied less. There is evidence that multicultural policy of society is related to positive attitudes towards migrants and a reduction in perceived threat. On the other hand, there is evidence that the open immigration policy of the society may be resisted by the some representatives of the host population. Based on data from European countries, we examined the relationship between the 8 indicators of immigration policy that make up the integration policy index (MIPEX) and the three variables that characterize attitudes towards migrants and migration (the permissibility of migration, the benefits of migration, institutional support for migration). In the study we used data from the integration migration policy index (MIPEX) for 2014, as well as indicators of attitudes towards migrants in 17 European countries according to the European social survey ESS (more than 30,000 respondents) for 2016. This design allowed us to divide the cause (immigration policy) and the possible consequence (attitudes to migrants). From the ESS data, we have chosen only the answers of the representatives of the ethnic majority. Multilevel structural equation modeling with MPLUS software
\end{abstract}


was used for data processing. The results of the study showed the ambiguity of the relationship of the MIPEX index and its components with different attitudes of the host population towards migrants and migration. The paper discusses which aspects of integration policy (on the example of European data) have a positive and which have negative relations with the attitudes of the host population towards migrants.

Keywords: multiculturalism, MIPEX, the migrant, attitudes towards migrants.

\section{References}

Bilgili, Ö., Huddleston, T., \& Joki, A.-L. (2015). The dynamics between integration policies and outcomes: A synthesis of the literature. Barcelona, Spain: Centre for International Affairs.

Bodziany, M. (2017). "Glass walls" - considerations about european multiculturalism. Sotsial'naia psikhologiia $i$ obshchestvo [Social Psychology and Society], 8(3), 20-30. doi:10.17759/sps.2017080303 (in Russian)

Bourhis, R.Y., Moïse, L.C., Perreault, S. \& Senécal, S. (1997). Towards an interactive acculturation model: A social psychological approach. International Journal of Psychology, 32, 369-386. doi:10.1080/002075997400629

Croon, M. A., \& van Veldhoven, M. J. P. M. (2007). Predicting group-level outcome variables from variables measured at the individual level: A latent variable multilevel model. Psychological Methods, 12, 45-57. doi:10.1037/1082-989X.12.1.45

Ely, R. J., \& Thomas, D. A. (2001). Cultural diversity at work: The effects of diversity perspectives on work group processes and outcomes. Administrative Science Quarterly, 46(2), 229-273. doi:10.2307/2667087

Favell, A. (2001). Integration policy and integration research in Europe: a review and critique. In T. A. Aleinikoff and D. B. Klusmeyer (Eds.), Citizenship today: global perspectives and practices (pp. 349-400). Washington, DC: Carnegie Endowment for International Peace.

Geddes, A. (2003). The politics of migration and immigration in Europe. London: Sage. doi:10.4135/9781446280492

Geiser, C. (2012). Data analysis with Mplus. New York: Guilford Press.

Ginges, J., \& Cairns, D. (2000). Social representations of multiculturalism: A faceted analysis. Journal of Applied Social Psychology, 30(7), 1345-1370. doi:10.1111/j.1559-1816.2000.tb02524.x

Hoyle, R. H. (Ed.). (2012). Handbook of structural equation modeling. New York: Guilford Press.

Jacobs, D., \& Herman, B. (2009).The nexus between immigrant integration policy and public opinion in the European Union. In J. Niessen \& T. Huddleston (Eds.), Legal frameworks for the integration of third-country nationals (pp. 113-140). Leiden: Martinus Nijhoff Publishers.

Jöreskog, K. G. (1993). Testing structural equation models. In K. A. Bollen \& J. S. Long (Eds.), Testing structural equation models (pp. 294-316). Newbury, CA: Sage.

Kaiser, C. R., \& Pratt-Hyatt, J. S. (2009). Distributing prejudice unequally: Do Whites direct their prejudice toward strongly identified minorities? Journal of Personality and Social Psychology, 96(2), 432-445. doi:10.1037/a0012877

Koopmans, R. (2013). Multiculturalism and immigration: A contested field in cross-national comparison. Annual Review of Sociology, 39, 147-169. doi:10.1146/annurev-soc-071312-145630 
Koopmans, R., Michalowski, I., \& Waibel, S. (2012). Citizenship rights for immigrants: National political processes and cross-national convergence in Western Europe, 1980-2008. American Journal of Sociology, 117(4), 1202-1245. doi:10.1086/662707

Plaut, V. C., Thomas, K. M., \& Goren, M. J. (2009). Is multiculturalism or colorblindness better for minorities? Psychological Science, 20, 444-446. doi:10.1111/j.1467-9280.2009.02318.x.

Richeson, J. A., \& Nussbaum, R. J. (2004). The impact of multiculturalism versus color-blindness on racial bias. Journal of Experimental Social Psychology, 40(3), 417-423. doi:10.1016/j.jesp.2003.09.002

Ryan, C. S., Hunt, J. S., Weible, J. A., Peterson, C. R., \& Casas, J. F. (2007). Multicultural and colorblind ideology, stereotypes, and ethnocentrism among Black and White Americans. Group Processes and Intergroup Relations, 10(4), 617-637. doi:10.1177/1368430207084105

Schlueter, E., Meuleman, B., \& Davidov, E. (2013). Immigrant integration policies and perceived group threat: A multilevel study of 27 Western and Eastern European countries. Social Science Research, 42(3), 670-682. doi:10.1016/j.ssresearch.2012.12.001

Stephan, W. G. (2014). Intergroup anxiety theory, research, and practice. Personality and Social Psychology Review, 18(3), 239-255. doi:10.1177/1088868314530518

Stephan, W. G., \& Renfro, L. C. (2002). The role of threats in intergroup relations. In D. Mackie \& E. Smith (Eds.), From prejudice to intergroup emotions (pp. 191-208). New York: Psychology Press.

Stephan, W. G., \& Stephan, C. W. (1985). Intergroup anxiety. Journal of Social Issues, 41, 157-175. doi:10.1111/j.1540-4560.1985.tb01134.x

Thomas, K. M., \& Plaut, V. C. (2008). The many faces of diversity resistance in the workplace. In K. M. Thomas (Ed.), Series in applied psychology. Diversity resistance in organizations (pp. 1-22). New York: Taylor \& Francis Group/Lawrence Erlbaum Associates.

Todd, A. R., \& Galinsky, A. D. (2012). The reciprocal link between multiculturalism and perspectivetaking: How ideological and self-regulatory approaches to managing diversity reinforce each other. Journal of Experimental Social Psychology, 48(6), 1394-1398. doi:10.1016/j.jesp.2012.07.007

Wolsko, C., Park, B., \& Judd, C. M. (2006). Considering the tower of Babel: Correlates of assimilation and multiculturalism among ethnic minority and majority groups in the United States. Social Justice Research, 19(3), 277-306. doi:10.1007/s11211-006-0014-8

Wolsko, C., Park, B., Judd, C. M., \& Wittenbrink, B. (2000). Framing interethnic ideology: effects of multicultural and color-blind perspectives on judgments of groups and individuals. Journal of Personality and Social Psychology, 78(4), 635-654. doi:10.1037/0022-3514.78.4.635

Wright, M., \& Bloemraad, I. (2012). Is there a trade-off between multiculturalism and socio-political integration? Policy regimes and immigrant incorporation in comparative perspective. Perspectives on Politics, 10(1), 77-95. doi:10.1017/S1537592711004919

Yogeeswaran, K., Dasgupta, N., \& Gomez, C. (2012). A new American dilemma? The effect of ethnic identification and public service on the national inclusion of ethnic minorities. European Journal of Social Psychology, 42(6), 691-705. doi:10.1002/ejsp.1894

Alexander N. Tatarko - professor, Faculty of Social Sciences, School of Psychology; chief research fellow, International laboratory for Socio-Cultural Research, National Research University Higher School of Economics.

Research area: social capital, social and psychological capital of the person, interethnic relations, values, acculturation.

E-mail: tatarko@yandex.ru 